problems. The ethnogenist, or human ecologist in Prof. Bews's sense, insists on the value of 'function' for survival, and claims that the diffusion of cultural elements by borrowing between races in contact is a process which involves the selection of some elements only, their modification or adaptation to the needs of the borrower and the complete rejection of incompatible elements. Methodologically, Prof. Bews accepts the reviewer's classification of culture by distinguishing the social inheritance of 'culture-forms' and of 'cultureaccessories' as well as the genetic inheritance of the 'culture-potential' of their culture-bearers; for at every stage culture is conditioned by the capacity of peoples to give expression to it (chapter vi).

The reviewer does not like the term 'ethnology' used as the equivalent for 'cultural anthropology' (p. 111). Ethnology is a term which should be restricted to the comparative and inductive science by which the races of mankind are compared, identified and distinguished. For the empirical and morphological sciences we have the terms 'ethnography' and 'demography'.

The book is well indexed, and bibliographies are appended to each chapter. In both index and the bibliographies there are, perhaps inevitably, some conspicuous omissions. A few authors who should certainly find a place are omitted, whilst some of us would hesitate to include others who are selected. Some of the authorities included in the bibliographies do not find a place in the general index even when they are mentioned in the text. But these are minor points. Anthropologists, archæologists and others must certainly read Prof. Bews's book.

\title{
Science for All
}

\section{More Simple Science:}

Earth and Man. By Prof. E. N. da C. Andrade and Prof. Julian Huxley. Pp. $\mathrm{x}+352$. (Oxford : Basil Blackwell, 1935.) $6 s$. net.

WE think it may be said, without exaggeration, that the average person knows very little about science and usually dislikes having anything to do with it. Frankly it bores him. A few years ago at the annual dinner of a scientific society, a Cabinet Minister, who was one of the guests, began his speech by apologising for his ignorance of science, and added that most of his knowledge of the subject was gleaned from the Illustrated London News! One can understand why our rulers often fail to appreciate the value of scientific methods, which often require them to take a long view, when applied to economic Empire development. It may be that much of this ignorance is due to the way men of science present their subject to the unscientific mind. Astronomy has been popularised, but there are many useful branches of science which have not been so treated, anyhow not in suitable language.

It is, therefore, a joy to read the book under review. The language is clear and easy, while there is behind every statement the weight of undeniable authority. Would that more men of science would take the trouble to do for the manin-the-street what Profs. Andrade and Huxley have done. This volume, mainly by Prof. Julian Huxley, forms part of a series of separate books adapted for schools, which the joint authors are undertaking, and is a continuation of, and com. plementary to, a previous volume entitled "Simple Science". The opening words of the first chapter describe its objects : "In this Book we shall deal with some of the rules about living things in their relation to the planet Earth which serves as their home, ending up with some facts concerning man in his relation to the earth and to other living creatures." Following on these lines there are chapters on the climates of the earth; simple statements on geological structure ; the chemistry of life, dealing with various cycles in the circulation of matter through life including an interesting section on the wastefulness of man; how soil is formed and the different kinds there are; plant food and fertilisers, plant life and scenery; the stream of life, the life story of an animal and its development ; animals and plants can change, and the deliberate improvement of living creatures.

The last two chapters are devoted to a sketch of the history of science through the ages, and how science has changed general ideas. "Science means finding out how things actually do happen, not laying down principles as to how they ought to happen."

As we have quoted the beginning of the volume we may now appropriately quote the end : "With. out science and the scientific spirit, we shall just drift along; with their aid, man may be able to learn to control his destiny." The illustrations, by L. R. Brightwell and Comerford Watson, are cleverly done and suit their purpose admirably.

As part of the acquisition of a useful general knowledge of science in schools, we could not recommend a better book than this. H. L. C. 